\title{
3 \\ Judging and the Scope of Mental Agency
}

\author{
Fabian Dorsch
}

\section{SOME DIVISIONS IN THE MIND}

Try to conjure up a visual image of a sunny forest, or to suppose that Goethe once visited Stoos in the centre of Switzerland. Presumably, you will be able to comply immediately and easily, without having to do something else first, and without having to invest too much effort. But then, try to conjure up a visual perception of a sunny forest, or to form the judgement that Goethe once visited Stoos, just like that - that is, without resorting to additional actions, such as travelling outside of the city, consulting a biography of Goethe, or taking a perception- or judgement-inducing drug. Presumably, you will fail.

What these examples suggest is that there is a fundamental - though perhaps not necessarily strict-divide among the phenomena making up our mental lives. On the one side, there are our deliberate and straightforward mental actions and the mental episodes which they produce (and sustain). Conjuring up an image or supposing that something is the case should count-if anything should - as paradigm instances of deliberate mental agency, namely as instances of the activity of imagining something. ${ }^{1}$ Very roughly, they are examples of agency because they rationally respond to and are guided and possibly justified by certain practical reasons (i.e. those provided to us by our desires or intentions to picture or suppose something); they constitute mental actions because they are aimed at the production of some mental phenomena (i.e. an image or a supposition), and because their performance does not involve bodily movements, but occurs exclusively within the mind; they are deliberate because they are done in full, attentive consciousness of the means, ends, and intended results involved; and they are straightforward-or 'light-fingered' (O'Shaughnessy 1980: 21-2) - in that they are not done by performing another action which deliberately exploits certain passive effects (such as those of emotional dispositions,

1 I defend the view that imagining is indeed a special form of deliberate and straightforward mental agency in Dorsch (2009). 
hypnosis, or judgement-inducing drugs). Indeed, our ability to imagine seems to reveal the extreme freedom which we may enjoy in our conscious mental lives. It is difficult to think of a domain of our agency with fewer restrictions or obstacles.

On the other side of the divide, there are the more passive mental phenomena, notably those of our mental episodes, the formation (and sustainment) of which is either not at all influenced by our mental agency, or only in a mediated — though usually still deliberate-way. Many episodes occur and disappear without any active involvement on our behalf. We are often overcome by feelings or sensations, surprised or annoyed by perceived smells or sounds, or find ourselves suddenly confronted with images, memories, or thoughts. Other mental episodes, however, are located in between deliberately formed images or suppositions and passively occurring feelings or perceptions, in that their occurrence or nature is somehow influenced by deliberate activity, but in a less straightforward or encompassing way than in the typical case of imagining. You may intentionally calm down yourself or improve your mood by actively imagining something relaxing or cheerful, such as walking through a quiet and sunny forest and attending to the pleasant and soothing sounds and smells of the environment. Or you may be able to decide when to judge an issue or to remember an appearance, and which issue to judge or whose appearance to remember. But despite the intended impact of mental or bodily agency on such episodes, they do not seem to allow for the straightforward control that we often, if not always, enjoy over what we imagine. In this respect, they are closer to episodes which occur completely passively.

My primary interest in this chapter is to get clearer about how, and where, best to draw the line between the straightforwardly active and the more passive aspects of our conscious minds. My main focus will thereby be on the question of whether judging can be as active as imagining: that is, whether we can form judgements in a deliberate and straightforward manner, or (as I will also say) voluntarily, or at will. The example above suggests that the answer should be negative, and that we cannot freely decide which particular proposition to endorse in a judgement concerning a certain issue.

Indeed, this opinion has been widely endorsed. ${ }^{2}$ But it has not often been explicitly argued for. And if it has, the arguments have typically made use of the controversial idea that judgements (or beliefs) are intrinsically and normatively linked to truth. I am sympathetic to the view that there is no real need to take up, but good reason to try to avoid, any commitment to such a norm for

2 See e.g. Williams (1973), Winters (1979), O’Shaughnessy (1980), Bennett (1990), Noordhof (2001), Engel (2002), Owens (2003), and Shah and Velleman (2005). Even thinkers, who are more sympathetic to the idea of voluntary formations of judgements or belief, often defend this possibility without accepting (or at least arguing for) the possibility of judgements or beliefs formed directly in response to the intention to do so (cf. Weatherson's (2007) discussion, and especially his contrast between voluntary and volitional agency). 
judgements (cf. Papineau 1999; Dretske 2000). And I will in addition illustrate, though only briefly, that the normative approach to the involuntariness of judgements faces a serious and not always noted problem.

As an alternative, I will present an argument which refers to the ways in which we consciously experience judgements and instances of deliberate mental agency. What is important about this argument for the involuntariness of judgements is not so much its perhaps uncontroversial conclusion, but rather the particular way in which it tries to support it. For it highlights the impact which conscious experience has on-as well as what this form of awareness can tell us about - the formation of judgements and the scope of deliberate mental agency. The resulting account is thus meant to be a promising competitor for theories which account for judgements and mental agency primarily in normative or functionalist terms.

The issue of whether we can form judgements at will can, as already suggested, be framed in terms of the question of whether the deliberate formation of a judgement can sometimes be as active as the conjuring up of an image or the making of a supposition, or whether instead it belongs always to the group of less active mental phenomena, which includes not only the passive cases of perceiving, sensing, or feeling something, but also the somewhat active cases of changing one's mood or bringing about the occurrence of an episodic memory. What distinguishes in particular the two ways in which we can deliberately influence the occurrence or nature of some of our mental episodes is that one is (as I have called it) more straightforward, or less mediated, than the other. Before I discuss both the normative and the experiential approach to the involuntariness of our judgements, it is perhaps helpful to say a bit more about what judgements are, and what characterizes straightforward deliberate agency.

Judgements - including occurrent beliefs — are mental episodes. As such, they are part of the stream of consciousness and of the same general kind of mental state as feelings, thoughts, sensations, perceptions, and so on. ${ }^{3}$ More specifically, judgements consist in the conscious taking of a propositional and conceptual content to be true, which means that they do not-like suppositions-merely represent things as being a certain way, but also make the claim that this is how things are. ${ }^{4}$ This is one important respect in which judgements differ from the events which constitute their formation (e.g. acts of judging): only the former,

3 What I label 'mental episodes', Wollheim calls 'mental states' (1984: 33-4). And I will use the latter expression to cover not only mental episodes or events, but also dispositional or standing states, such as beliefs, desires, and so on. Accordingly, my talk of 'states' is not intended here as involving any commitment to a certain ontological category — such as to their being states of affairs, rather than events, activities, or processes.

4 This does not suffice to distinguish judgements from guesses. What is needed in addition is that it is constitutive of a guess, but not of a judgement, that it originates in the conscious practical or arbitrary choice of one or another from a certain range of propositions, none of which are sufficiently supported or forced upon us by the evidence available to us, but which may none the less be among the acceptable options of choice only because they all enjoy at least some evidential backing. 
but not the latter, are instances of episodic and committal thought. Another is that, while events of forming a judgement are often, or perhaps even always, instantaneous, the formed judgements may remain in continuous existence for a considerable amount of time. Our judgement that the person opposite us is very attractive, for example, may stay in the background of our conscious mind during our evening-long conversation and constantly influence what we say to, and how we treat, her or him. ${ }^{5}$ And the same is true of many of our judgemental endorsements of the propositions which we use as premisses in more complex instances of reasoning.

The contrast between straightforward and mediated deliberate agency, on the other hand, is best drawn - at least for the current purposes - in terms of the fact that, while the latter involves the instrumental reliance on certain epistemic or merely causal processes and their passive effects, the former does not. The relevant processes are thereby characterized by the fact that, once they are triggered by us and progress normally, they lead by themselves - that is, without further help or involvement of agency or other factors external to them - to the desired or intended outcome. And to instrumentally rely on such processes means here to employ them as means in relation to their sufficiency, once triggered and progressing normally, to bring about the desired or intended outcome. What this involves, more specifically, is that we take the respective processes to be instrumental in achieving our goal; that we take them to be so partly by recognizing their capacity to lead by themselves to the desired outcome; and that we try to act on our relevant desires or intentions by means of trying to trigger the processes in question. Accordingly, an instance of deliberate agency aiming at the production of a mental phenomenon is mediated-and not straightforward-just in case the agent attempts to achieve this aim by trying to employ an epistemic or merely causal process as a sufficient means for bringing about the desired mental phenomenon. Any other involvement of epistemic or merely causal factors is compatible with both kinds of deliberate mental agency.

Consequently, we may still rationally endorse a proposition in a guess - but presumably not in a judgement - even when the proposition lacks sufficient epistemic support (cf. Owens 2003).

The offered characterization of judgements is also meant to focus the current discussion exclusively on kinds of judgement which are truth-apt and to be formed and assessed in relation to epistemic reasons. Whether this includes normative judgements (e.g. about what one ought to do, how things ought to be, or what is good) or judgements linked to or identified with intentions (e.g. about what one will do) depends on whether the correct account of these judgements will understand them as truth-apt and epistemic, or rather as expressive or as practical. However, my hope is that our experience of them as being formed in response to reasons - whether these are epistemic or practical - is also incompatible with any experience of them as being formed in a straightforward manner; and that this provides us again with an argument for their involuntariness. See Pink (1996) for an excellent discussion of, as well as a slightly different argument for, the involuntariness of decisions, desires, and normative judgements which are formed — or at least meant to be formed - in response to practical reasons.

5 Thanks to Kevin Mulligan for suggesting this example. 
For example, when we deliberately attempt to recall the appearance of a certain person, we thereby set in motion certain epistemic mechanisms because we expect them to force a specific image onto us that is likely to be accurate. If we lacked this expectation, we would probably often not bother engaging our memory, but instead opt for our ability to imagine appearances. And something very similar happens when we decide to judge an issue on the basis of the evidence available to us: we thereby assume that the proposition, which the evidence will compel us to endorse due to some underlying epistemic processes, will probably be true. ${ }^{6}$ Similarly, we can reasonably decide and try to cause a change in our mood by imagining a certain scenario only if we believe that performing the latter action is likely to be instrumental in bringing about the desired alteration of how we feel. Otherwise, there would be no reason for us to engage in the imaginative activity in response to our wish to alter our mood. And when we deliberately take a drug in order to cause in us certain hallucinations, we do this precisely because of our reasonable expectation that the respective causal mechanisms, thereby triggered by us, are very likely to lead to the occurrence of such hallucinations. In the absence of this expectation, we normally would not take the drug, or at least not with the aim of hallucinating.

Imagining something, in contrast, does not involve similar instrumental beliefs about and exploitations of epistemic or merely causal mechanisms. Although straightforward agency may allow for the influence of, or even conscious reliance on, epistemic factors, this kind of influence appears never to be mediated by an epistemic process which is - or, at least, which we instrumentally believe to be-sufficient on its own to lead to the occurrence of whichever mental phenomenon has been wished for. Our successful attempt at visualizing a sunny forest, say, may very well be informed by our knowledge of how sunny forests look like, or of what it would be like to see a sunny forest. But the influence of this kind of knowledge on the resulting visual image is not mediated by (an instrumental belief about) a rational process pertaining to epistemic rationality which, once actively triggered, is alone responsible for the occurrence of the image. In particular, we do not form the visual image in response to our

6 What happens in these cases is perhaps that our sole reason to rely on epistemic processes is that we are interested in producing true representations, and that we take epistemic processes (and nothing else) to be truth-conducive. But instead, it might also be a fact that basic cases of reliance on epistemic mechanisms within mediated mental agency do not actually involve the instrumental understanding and employment of the respective epistemic mechanisms. When we, say, begin to act on our decision to recall the appearance of a friend, we perhaps might not have to possess or use the instrumental belief that a good way of achieving this goal is to actively trigger the respective underlying mnemonic mechanisms. If this should turn out to be true, the characterization of the difference between straightforward and mediated agency would have to be refined accordingly - for instance, by weakening the respective condition to the effect that only the possibility, but not the actuality, of instrumental employment of the processes is to be taken into account; or by supplementing it with the condition that, if epistemic factors are concerned, it is alone decisive whether these are in fact triggered by our active engagement and furthermore by themselves sufficient to bring about the desired outcome, once started and progressing normally. 
current recognition of some epistemic reasons (as in the case of the formation of judgements on perceptual or inferential grounds). And the occurrence of the visual image is not the direct result of a mechanism meant to preserve a rational link to epistemic reasons recognized in the past (as in the case of episodic memories based on past perceptions).

Similarly, it may be true that, when we successfully visualize a sunny forest, our employment of our capacity to visualize sunny forests is causally responsible for the occurrence of the respective visual image. And this again may involve, or be grounded in, more fundamental causal chains. But in order to successfully act on our intention to visualize a sunny forest, we need not, and do not, conceive of the causal processes concerned as sufficient means. We may take the employment of our capacity to visualize sunny forests to be a necessary part of visualizing a sunny forest, and we may even understand what we are then doing as the action of visualizing a sunny forest by means of actively making use of the respective capacity. But we do not thereby think of the link between our employment of this capacity (or similar capacities, such as the capacity to visualize trees) and the occurrence of the visual image in both causal and instrumental terms (if we think of the link or its potential causal nature at all). In particular, we do not form the intention to use our capacity to visualize sunny forests in rational response to our intention to visualize a sunny forest and an instrumental belief that making active use of this capacity is likely to cause the occurrence of the desired visual image. In fact, we would not know what it would mean to act on the intention to use our capacity to visualize sunny forests, if not to act on the intention to visualize one or more sunny forests. ${ }^{7}$

\section{THE NORMATIVE APPROACH}

In the light of the preceding considerations, the main task in the formulation of an argument for the claim that judgements can be formed at will is the identification of a constraint on all possible judgements, which puts them beyond our deliberate and straightforward control: that is, which prevents them from being consciously formed by us in direct response to our desire or intention to form them, without any instrumental exploitation of passive processes. If the constraint would not apply to all possible judgements, it could not completely account for the fact (assuming that it is one) that none of them can be formed by us at will, including the unconstrained ones. Furthermore, the constraint has to concern the ways in

7 Note also that the case of visualizing someone by means of visualizing a portrait of this person still counts as an instance of straightforward agency, given that visualizing the portrait is neither epistemic, nor merely causal in nature, but instead itself a straightforward action. As a result, not all instances of straightforward agency need to be basic in the sense of not being performed by doing something else. 
which judgements can be actively formed: it has to limit these ways in such a manner as to rule out the possibility of a deliberate and straightforward formation of judgements.

The most prominent strategy has been to derive such a constraint from the assumed fact that judgements are normatively linked to, or aim at, truth in such a way that they are subject to the following truth norm: ${ }^{8}$

(TN) Judgements ought always to be true, and to be formed only if they are true.

This truth norm is usually introduced for very different purposes, such as to capture the essence of judgements (or beliefs), or to account for their representationality and their link to truth (cf. Papineau (1999) and Dretske (2000) for a detailed discussion). That it may also figure in an account of the involuntariness of judgements is often only noted as an aside-if it is noted at all. But the truth norm is none the less predestined for playing this particular role because, when formulated in terms of (TN), it purports to achieve two things: to govern all possible judgements; and to put a restriction on the ways in which we can deliberately form them.

But not just any understanding of the truth norm and its impact on judgements can help in explaining the involuntariness of judgements. In particular, it does not suffice to identify the constraint on judgements and their deliberate formation, as it arises out of their assumed subjection to (TN), with the demand that, when deliberately forming a judgement (in contrast to another kind of mental episode), we should act on the aim to form the respective mental episode only if it is true. According to this demand, it is better or more appropriate to pursue truth as one's goal when deliberately forming a judgement. But it is not necessary, given that the possibility of violating the demand is not ruled out. Although one would be somehow at fault or irrational when ignoring or not following the demand, whether one satisfies it has no influence on whether one counts as deliberately forming a judgement. As a consequence, the demand does not really limit the ways in which judgements may be deliberately formed, it puts a restriction solely on when such an intentional formation may count as proper. It is, accordingly, not strong enough to prevent the occurrence of judgements which are formed entirely at will.

Therefore, the constraint on judgements derived from (TN) has to be understood in stronger terms. The most natural way of strengthening the condition on how we can deliberately form judgements seems to be to modify it

8 See, for instance, Williams (1973) and Shah and Velleman (2005) for defences of this strategy and the kind of normativity involved, and Winters (1979), Bennett (1990) and Engel (2002) for critical discussions. See also Burge's writings, Peacocke (1998), Wedgwood (2002) and Shah (2003) for endorsements or explications of the idea that beliefs are subject to a truth norm, and that conformity to this norm requires us to believe something only if it is true. It is not unlikely that they will be sympathetic with the normative approach to the involuntariness of judgements. 
in such a way that its satisfaction becomes constitutive of the deliberate formation of a judgement, instead of merely rendering examples of it appropriate. ${ }^{9}$ The result will be something like the following requirement:

(C) Deliberately forming a judgement requires acting on the aim to form it only if it is true.

Thus, if we do not have this goal in mind and do not actively and consciously try to achieve it, then we are not engaged in the deliberate formation of a judgement - although we still might be engaged in the intentional or active formation of a mental episode of another kind (e.g. a supposition), or experience the passive occurrence of a judgement.

Understanding the constraint in this way does indeed promise to establish its incompatibility with any potential straightforward voluntariness of judgements. It seems plausible to say that deliberately acting on the aim to form a mental episode only if it is true requires making use of truth-conducive means. And, it may be further argued, reliance on truth-conducive means renders the respective mental agency mediated in the sense specified above. The idea is that only the reliance on epistemic reasons is likely to result in the formation of a true mental state. For, the assumption goes, there do not appear to be truth-conducive means other than epistemic considerations. Hence, the requirement $(\mathrm{C})$ comes down to the demand that the deliberate formation of judgements has to happen by means of passive — namely epistemic_processes: judgements have to be deliberately formed on the basis of epistemic reasons (if they are to be deliberately formed at all). It follows from this that we cannot deliberately form judgements in a straightforward manner. ${ }^{10}$

But the constraint (C) does not apply to all possible or even all actual judgements. Paradigm examples of judgements, which are successfully formed in deliberate response to the desire or intention to form them, but without the aim in mind to form them only if they are true, are manipulative or induced judgements. Manipulated judgements are based on evidence, the collection of which involves ignoring evidence of a certain kind, or unproportionally or exclusively seeking evidence of another kind. Here are some good examples: ${ }^{11}$

Consider people who aim deliberatively to mislead themselves. Suppose an elderly man realises that he is likely to be upset if he learns about the real probability of his developing

9 Williams (1973) can plausibly be read as adopting this strategy (cf. also Winters 1979).

10 This argument is very similar to one of the arguments for the same conclusion in Williams (1973), only transposed from the conceptual level to the level of constitution (cf. my discussion in the last section). Proust (Ch. 13 below) presents a slightly different argument, the central idea of which seems to be that the aim of truth does not allow for the freedom of choice essential to deliberate agency.

11 See O'Shaughnessy (1980), Owens (2000), Shah (2003) and Shah and Velleman (2005) for further examples of manipulated judgements, or 'wishful thinking'. Wedgwood (2002) also mentions the possibility of acting on one's intention to cease or avoid having a certain belief. 
cancer, and so arranges to avoid any evidence that might undermine his sanguine belief that this probability is low. Or suppose an adolescent youth learns that people with an inflated view of their own worth are generally happier and more successful, and so deliberately seeks out evidence which will make him think overly well of himself. Of course, there are familiar psychological difficulties about deliberately arranging to have false beliefs, but examples like this suggest they are not insuperable. (Papineau 1999: 24)

There are probably many other, and possibly more radical, ways in which we can manipulate our evidence, other than by being unduly selective. For instance, we may ignore the lack of quality of some pieces of evidence (e.g. by relying on untrustworthy sources), or may invent or misread some of them (e.g. by misinterpreting emotional feelings as evidence). By contrast, induced judgements are formed in much simpler ways: they are not evidentially based, but instead occur as the product of some causal process which is intentionally triggered by some action of the subject in question. Examples of induced judgements would be those which would occur as the effect of the intake of a suitable drug, or of the visit to a hypnotist. They have in common with manipulated judgements that, often, they are deliberately formed without the aim of truth in mind. And although they may, as a consequence, end up being epistemically inappropriate, this does not undermine their possibility.

One might wish to insist that cases of manipulated or induced judgements do not really constitute counter-examples to (C), either because the mental episodes involved are not really judgements, or because they are not really actively or deliberately formed, so that their formation does not have to meet the necessary condition on the deliberate formation of judgements established by the constraint. ${ }^{12}$ But it seems entirely ad hoc to claim that the examples do not concern judgements, given that the mental episodes in question endorse a proposition as true and are phenomenologically indistinguishable from more typically formed judgements (cf. Winters 1979 and Engel 2002). And the view that manipulated or induced judgements are not formed in an active and deliberate manner appears equally implausible. It is true that the agency involved leads to the occurrence of the judgement only in a mediated way. But something very similar is true of many other cases which we are normally happy to classify as deliberate actions. If bringing about the occurrence of a specific judgement by intentionally taking a drug in the full knowledge and reasonable expectation that this intake is likely to lead to the desired occurrence of the judgement is indeed

As O'Shaughnessy and Papineau observe, the intentional manipulation of one's judgements may require a certain amount of self-deception.

12 In personal conversation, Shah mentioned that he is inclined to the view that the formation of manipulated or induced judgement should not count as an instance of (deliberate) agency. Indeed, he and Velleman seem to have to adopt this line of response, since they acknowledge the possibility of these types of judgements, but also believe that judgements cannot be formed at will because of their special normative nature described by (TN) (cf. Shah 2003; Shah and Velleman 2005). 
not taken to constitute an action, then bringing about the death of a person by pulling a trigger or bringing about the arrival of a letter by posting it should not count as deliberate actions either.

Of course, the occurrence of the judgement is itself not an action. But neither is the occurrence of the death of the person, nor the arrival of the letter (at least not regarding the person who has sent it). Instead, what is actively done by the subject in question is the intended and expected bringing about of the occurrence of these passive events. And the subject performs this complex action-which may reasonably be described as the forming of a judgement, the killing of a person, or the sending of a letter-by performing a much simpler action, namely the taking of the drug, the pulling of the trigger, or the posting of the letter. It might still be attempted to maintain that, in general, there are no complex, but only simple actions; and that the latter do not allow for individuation and description in terms of their intended and expected causal consequences. But then, the formation of the judgement, the killing of the person, and the sending of the letter would still be on a par, since they all would equally not count as actions. And this result would fatally clash with our ordinary treatment of events of shooting someone or sending a letter — and not only of events of pulling a trigger or posting a letter-as instances of agency. ${ }^{13}$

The only significant difference between the two kinds of cases is that the occurrence of the judgement, but presumably not the occurrence of the death or the arrival of the letter, presents itself phenomenally to the agent as passive. ${ }^{14}$ However, this is not the result of the judgement perhaps being brought about non-intentionally, or less actively than the two external events, but instead due to the fact that the judgement is part of the conscious mind of the subject and thus accessible to him in a different way than the external events. If he were able to become aware of the latter in the same way, he probably would experience them as passive as well. Moreover, the fact that the judgement is part of the subject's own mind, and not of another's, seems irrelevant for whether knowingly and expectantly bringing about of a judgement by, say, the administering of a drug should count as an action. None the less, this difference in how we are

13 Even proponents of the view that only tryings are actions often enough permit that action descriptions can apply to complex events consisting in tryings and their causal results, as long as there is a suitable or non-deviant causal link between the two (cf. Hornsby 1980: 122-3; also O'Shaughnessy 1980).

14 Another difference - though probably cutting across the cases - is that we do not always have established action terms available to directly pick out the more complex actions. We call the action of deliberately bringing about the death of a person by doing something simply a 'killing'. But there is no such action term for the action of deliberately bringing about the sleep of a person (e.g. oneself) by administering a drug to her. And the expression 'forming a judgement', as used for the action of deliberately bringing about the occurrence of a judgement by taking a respective drug, is probably not commonly understood as an action term. Note, however, that the last term, as well as the related expression 'the formation of the judgement', is meant here to pick out the event of doing something in order to cause the occurrence of a certain judgement, and not merely the event of this judgement occurring. 
aware of judgements and external events may still ultimately explain why we may have the intuition that murdering a person or sending a letter have more right to count as actions than forming a judgement in one of the mediated ways mentioned.

It is conceivable that the truth-related normativity of judgements may give rise to requirements other than $(\mathrm{C})$. But it is doubtful that any of them can be both weak enough to apply to all possible judgements, and strong enough to be incompatible with the deliberate and straightforward formation of judgements. In addition, the strategy of taking some constraint like (C) to be responsible for the involuntariness of judgements faces other difficulties, some of which I want to briefly mention.

A first challenge is to provide independent support for the claim that judgements are normative in the sense described. Critics of this idea have pointed out that it suffices for a satisfactory account of judgements (or beliefs) — which can explain, for instance, what differentiates judgements from other mental episodes, or how they represent the world - to assume that they have certain (evolutionary evolved) functions, notably the function to be true. This picture treats truth as a value for judgements, but as a value among many, which may be outweighed or undermined by the other values and thus need not always bind judges. That is, the latter need not always, when deliberately forming a judgement, be under the obligation to form it only if it is true. Accordingly, if the formation of a judgement is subject to such a truth-related obligation, this cannot be due to the general, intrinsic nature of judgements, but has to derive from something else, such as the wider practical purposes which are linked to the occurrence of the particular judgements in question, and which may differ greatly from case to case (cf. Dretske 2000; Papineau 1999). Another difficulty for the normative approach is to show how the requirement $(\mathrm{C})$ can actually be derived from the truth norm (TN) - and if this fails, how it might be established on other grounds. And a third challenge is to demonstrate that intentionally grounding judgements in epistemic reasons is indeed a-and, moreover, the only-truth-conducive means available to us. In fact, it has been be doubted that deliberate reliance on epistemic reasons can function as an instrumental means to truth - at least, if the latter is to be understood as one of our purposes among many others (cf. Owens 2003).

\section{THE EXPERIENTIAL APPROACH}

That the normative approach arguably fails in its attempt to establish a constraint on our deliberate formation of judgements, which prevents it from being straightforward in all possible cases, provides a good reason to look for an alternative account. But the search for such an account is also, and independently, motivated by the reasonable expectation and hope that theories which deny (TN) 
on other grounds should be able to account for the involuntariness of judgements as well as their norm-orientated competitors. My aim is therefore to pave the way for an argument showing why we cannot form judgements at will, which refers to the phenomenal character of judgements instead of their normativity.

This argument can be summarized as follows. Its starting point is the idea that we consciously experience our judgements always as epistemically motivated, while we consciously experience the straightforward results of our deliberate mental agency always as practically motivated. But, the reasoning continues, experiencing a mental episode as practically motivated rules out experiencing it as epistemically motivated-at least, if the episode concerned has been formed in a deliberate and straightforward manner. For experiencing such an episode as practically motivated means in fact experiencing it as immediately responding to the practical motives in question. And the phenomenal aspect reflecting this immediacy is incompatible with another potential aspect of experience, namely that aspect which reflects epistemic motivation. Hence, our judgements cannot result in a straightforward manner from our deliberate mental agency-which means that we cannot form them at will.

It will become much clearer in due course, I hope, how precisely each of the premisses involved in this argument should be understood, and also how they may be defended. But the core idea of this argument is that we experience certain conscious mental phenomena - such as judgements or mental actions - as rationally motivated. This means, first of all, that these phenomena possess a phenomenal or experiential character: they present themselves in phenomenal consciousness, or are experienced by us, in a specific way; or, as I will also say, they are phenomenally marked or revealed as being a certain way. ${ }^{15}$ The core idea implies furthermore that the phenomenal characters of the phenomena in question are of a particular kind: they involve a rational dimension or aspect which reflects their rational nature. More specifically, the conscious mental phenomena concerned are phenomenally marked as standing in a certain kind of rational relation: we experience them as motivated by-that is, as rationally based on and occurring (or having occurred) in response to-reasons. ${ }^{16}$

15 My use of the term 'experience' is perhaps unusual in that it refers to phenomenal consciousness rather than sensory experience. But it is akin to the German Erlebnis or erleben (especially as used by phenomenologists, such as Husserl) and will much simplify the presentation of the experiential approach. Other attempts at the notoriously difficult task of describing phenomenal consciousness have characterized it in terms of how it is or feels like to undergo, or be in, the respective events or states. Besides, I will leave it open whether the phenomenal character of episodes can remain unnoticed, or whether phenomenal consciousness always involves or requires some form of attention. This is unproblematic because forming a judgement deliberately, or 'in full consciousness' (cf. Williams 1973), will include attending to the judgement and the agency involved (cf. Peacocke (1998) and O’Brien (2003) for a discussion of this kind of attention).

16 As I understand motivation here, it is equivalent to actual responsiveness to reasons, in the sense that a mental episode or event is rationally motivated if it is initiated, guided, or otherwise rationally determined by certain reasons. By contrast, in many meta-ethical discussions, the notion 
In what follows, I will simply assume that judgements, mental actions, and the mental episodes which are the straightforward results of the latter are phenomenally conscious, or part of the stream of consciousness, and thus possess an experiential character. I will have to leave the defence of this assumption for another occasion. ${ }^{17}$ Here, I will merely try to soften related doubts by making clear that assuming the experiential form of awareness at issue is less demanding than might be thought.

First, enjoying this kind of awareness need not require any specific conceptual capacities, even if describing it in terms of experiencing an episode as being a certain way might be taken to suggest just this. Saying that we experience certain mental episodes as responding to reasons does not mean more than saying that their phenomenal character shows a specific aspect, that the phenomenal character of other episodes lacks this aspect, and that this phenomenal difference somehow reflects the corresponding difference in origin and determination. In a similar way, we experience red-perceptions as representing a different colour than green-perceptions, or certain feelings as more pleasant than others. And although it should usually be possible for us to conceptualize such phenomenal differences in introspective higher-order judgements, such a conceptualization does not necessarily already happen on the phenomenal level.

Second, the form of awareness in question is minimal in the sense that we can experience a mental episode or event as rationally motivated without being aware of, or otherwise able to identify, the respective reasons. For instance, when asked what the capital of Ecuador is, we may form and rely on the judgement that it is Quito-say, as a manifestation of some previously acquired belief-without being able to remember when or how we learnt this fact (e.g. whether from listening to a teacher, from reading a book, or from looking at a map; cf. Wedgwood 2002: 20). And it commonly happens to us that we perform an action, such as entering a certain room, and recognize it as been done deliberately by us, although we have forgotten why we did it. Moreover,

of 'motivation' is used in a more narrow and perhaps more technical sense, being limited to what I call 'practical motivation'. Furthermore, I am not concerned with 'motivation' in the sense of having a certain desire or intention which has not (yet) become motivationally effective. And I also take it that there are important and phenomenally salient differences between epistemic and practical motivation - if only due to important differences between the respective kinds of reasons or rationality. One such difference is, for instance, that while practical ends may often be achieved in many different ways, reaching epistemic ends (i.e. truth or epistemic appropriateness) seems to always require the reliance on evidence. And while our various practical ends interact with each other (e.g. by outweighing or supporting each other), the epistemic ends appear to be completely independent and isolated from them (cf. Owens 2003).

17 The assumption has been doubted, in particular, with respect to judgements. But most of the related debate has concentrated on whether judgements possess a distinctive phenomenal character, or whether differences in conceptual contents are phenomenally salient (cf. the discussions in Siewert 1998; Carruthers 2000), neither of which I assume here (cf. below) - though I defend, together with Gianfranco Soldati, both claims in Dorsch and Soldati (2004). 
even when we are aware of the motivationally effective reasons and their specific nature, this awareness need not be experiential.

Third, experiential awareness may be fallible in at least two respects. In both cases, the phenomenal character of the episode or event concerned fails to adequately reflect its nature. But the reasons for this are different. On the one hand, this failure may be due to the fact that the episode or event in question does not live up to how instances of the mental type, to which it belongs, phenomenally purport to be. We may, for example, experience a judgement as a judgement and, hence, as responding to epistemic reasons, although it has been purely causally induced (e.g. by a drug, or by an emotion). On the other hand, the failure may stem from the fact that we erroneously experience an episode or event, not as an instance of the mental type to which it belongs, but as an instance of another type. We may, for example, experience a judgement as being a supposition - that is, we may experientially mistake a judgement for a supposition - and thus fail to experience the judgement as epistemically motivated. ${ }^{18}$

Correctly speaking, my main claim should therefore rather be that, if we experience a judgement as a judgement, or an instance or product of straightforward and deliberate mental agency as such an instance or product, then we always experience it as purporting to be rationally motivated. In other words, it is essential to how we experience episodes as being judgements, or alternatively as being part of straightforward and deliberate mental agency, that they present themselves phenomenally as occurring in response to reasons. But out of simplicity, I will continue to say that we always experience judgements, deliberate mental actions, and their straightforward results as rationally motivated.

And fourth, the conscious phenomena in question need not possess distinctive phenomenal characters, in terms of which they can be individuated and differentiated from other phenomena. Judgements, for example, need not phenomenally differ from other mental episodes which may also be experienced as epistemically motivated (e.g. perhaps, episodic memories); and they need not phenomenally differ among themselves, even if they differ, say, in content, origin, or motivation. All that is claimed is that judgements are experienced as supported by epistemic reasons. And similar considerations apply to our experience of deliberate mental actions and the mental episodes which they produce.

18 The many examples of mainly pathological dissociations between our agency and our awareness of it (e.g. those mentioned in Wegner (2004) and discussed in his book) will also fall into one or the other category. The latter possibility of error would probably require, however, that episodes could be recognized and identified as judgements by reference to features other than their being actually experience by us in a certain way-for instance, in terms of their role in the acquisition of relevant beliefs or the performance of certain actions. And this might very well mean again that it is not essential to judgements that our actual experience of them shows some specific and distinctive aspects (though it may still be essential to them that they are consciously experienced in some way or another). More on the fallibility of experience and its relevance for the issue of involuntary judgements can be found at the end of sect. 6 . 


\section{OUR EXPERIENCE OF JUDGEMENTS}

What I want to try to defend first is the idea that the experiential character of our judgements always possesses a certain epistemic dimension: we experience our judgements as occurring in response to epistemic reasons. My defence makes essential use of an argument for the further claim that we experience judgements as epistemically reasonable, that is, as sufficiently supported by epistemic reasons. ${ }^{19}$ This round-about strategy is possible because the two aspects of the experiential character of judgements concerned correspond to two intimately connected aspects of the epistemic status of judgements. Being reasonable is, for a judgement, partly a matter of being motivated by reasons, given that only (or at least primarily) motivating reasons contribute to the rational standing of a judgement. If I judge that something is coloured on the basis of my unjustified belief that it is green, my judgement will not be justified either, even if there is a motivationally ineffective, but good reason for forming this judgement available to me (e.g. the object may indeed be green, and I may generally be in the position to recall one of my correct past perceptions of it or simply to look at it again). Hence, if judgements turn out to be marked in phenomenal consciousness as reasonable, it is to be expected that they will also be phenomenally marked as rationally motivated. If it therefore can be made plausible that we are, in some way or another, aware of judgements as reasonable, this should provide substantial support for the claim that we are, in the same way, aware of them as being motivated by reasons. In particular, experiencing a judgement as rationally motivated would seem to be part of experiencing it as reasonable.

My argument begins with the observation that we take our judgements to be epistemically reasonable, at least as long as we are not aware of defeaters or do not otherwise begin to doubt the epistemic standing of the judgements in question. If we would not take our judgements to enjoy such reasonableness, we probably would not rely on them as a provider of reasons for belief or action, in the sense that we would not let them rationally contribute to our acquisition of the corresponding non-occurrent beliefs or, by means of further theoretical or practical deliberation, to our acquisition or revision of other judgements, beliefs, or intentions. Instead, we would be inclined to revise them or give them up, or indeed would have refrained from forming them in the first place. That we-at least initially — take our judgements to be reasonable becomes also apparent in cases in which we come to doubt the epistemic reasonableness of one of our already existing judgements - say, because we begin to question the

19 In fact, these two phenomenal aspects seem to be part of an even richer epistemic dimension of the experiential character of judgements, consisting in our phenomenal awareness of them as providing reasons for belief or action. 
quality of the supporting evidence, recognize some fault in the cognitive processes originally involved, or simply encounter an opposing view. The occurrence of such a doubt presupposes that we are already aware of an initial claim to reasonableness, which then becomes the subject of the doubt. In particular, doubting a judgement on the grounds, say, that the perceptual conditions are inadequate requires being aware of the fact that the judgement in question has enjoyed rational support by a perception had under those inappropriate conditions.

The observation that we take our judgements to be reasonable and, as part of this, to be rationally motivated fits well with two other observations, namely that we take our judgements to have occurred passively, and that we take them to amount to knowledge (or at least to purport to do so) and treat them accordingly - for instance, when we rely on them in the acquisition of beliefs or the formation of intentions - even if they do not constitute knowledge (cf. Williamson 2000; Wedgwood 2002; Hornsby 2005). It seems that we are aware of our judgements as passive precisely because of-and perhaps even by - being aware of them as based on epistemic reasons, that is, as determined by passive epistemic processes. And assuming that knowledge requires both truth and epistemic appropriateness, taking our judgements to be instances of knowledge appears to involve taking them to be both true and reasonable. Indeed, if it is furthermore accepted that the fact that judgements endorse a proposition as true, and thus make a claim about how things are, is phenomenally salient and distinguishes them experientially from, say, suppositions (cf. Dorsch 2005), it seems very plausible that the other aspect of the epistemic status of judgements - that is, their reasonableness - should also be perspicuous in this way. The idea is that, by presenting themselves in phenomenal consciousness as instances of knowledge (independently of whether they in fact amount to knowledge), judgements make two salient and interrelated claims to rationality: that they represent adequately how things are; and that they are thereby sufficiently rationally supported.

But a sceptic concerning the experiential awareness of the prima facie reasonableness of judgements is probably also a sceptic concerning the experiential awareness of their claim to truth and knowledge. Therefore, I would like to put forward another line of reasoning, according to which our primary awareness of the reasonableness of our judgements should be best understood as a form of experiential awareness, given that all plausible alternatives appear to be untenable. There seem to be two plausible competitors to this view: the inference model and the prompting model. ${ }^{20}$ Both these models have in common that they take the awareness at issue to be the higher-order judgement that the

20 Other candidates seem to be even less attractive (cf. O'Brien 2003), in particular the idea that the awareness in question is a matter of some internal form of perception or observation (cf. Shoemaker 1994; Burge 1996; Martin 1997). 
respective lower-order judgement is epistemically reasonable. But they differ in their account of how we come to form that judgement.

The inference model maintains that the higher-order judgement under discussion is the result of a complex cognitive process. More specifically, it states that we infer the prima facie reasonableness of our judgements. For instance, we may believe that our judgements are generally reasonable as long as there are no relevant defeaters or doubts, and we may introspectively recognize that the mental episode in question is a judgement and that we have not been aware of any relevant defeaters previous to our doubts. Or, alternatively, we may remember how we have formed a judgement on the basis of certain pieces of evidence, and we may recognize that we have taken this formation to be epistemically appropriate, or at least have remained unaware of any inappropriateness, at the time of its occurrence. In both cases, we can then conclude that the judgement concerned has some claim to reasonableness.

However, that our primary awareness of the reasonableness of judgements is often not the result of such inferences is illustrated by cases in which we are ignorant about the general reasonableness of judgements, or about the particular epistemic origin of the judgement at issue. The view that our judgements are generally reasonable, as long as there are no defeating factors or circumstances present, seems to be sufficiently complex and non-obvious for many subjects (such as children) to lack it - in particular, since it requires a substantial amount of theorizing (assuming that it is not based on how we consciously experience judgements) and the possession of certain more technical concepts (such that of a defeater). But this does not seem to prevent those subjects from taking their individual judgements to be reasonable and to rely on them as providers of reasons for belief or action. Similarly, as already illustrated above, we may not remember what has ultimately provided support for our judgements and the beliefs which they may manifest. But we may still take them to be reasonable and trust them in our reasoning. And finally, our awareness of the reasonableness of our judgements often occurs too immediately to involve, or be preceded by, inferences of the kind described - for instance, when we enjoy such an awareness as part of coming to doubt the epistemic standing of a given judgement in direct reaction to, say, hearing a contradicting opinion or realizing that circumstances have been rather non-standard.

The prompting model, in contrast, claims that the higher-order judgement at issue (or a corresponding intuitive seeming ${ }^{21}$ ) occurs spontaneously, once we begin to wonder whether the lower-order judgement is reasonable. According

21 The prompting model invites characterization in terms of intuitions. Depending on one's understanding of them, either the higher-order judgement itself, or some spontaneously occurring rational seeming, on which the higher-order judgement is directly based, may be said to be intuitive (cf. the essays in Bodrozic 2004)). In the latter case, my arguments against the prompting model will concern the spontaneously occurring seemings, rather than the higher-order judgements grounded in them. 
to this view, the higher-order judgement is neither based on some inference or observation, nor simply the manifestation of a prior belief. Moreover, it is not based on the conscious experience of the reasonableness of the lower-order judgement. Otherwise, the experience would enjoy primacy over the higherorder judgement, and we would have the experience, rather than the prompting, model. Instead, the higher-order judgement is automatically prompted by our wondering about the epistemic status of the lower-order judgement in virtue of some reliable internal mechanism.

This internal mechanism cannot plausibly be due to some constitutive link between the lower- and the higher-order state. It does not seem to be true, for instance, that-assuming that we are rational and possess the required concepts - the presence of the lower-order judgement entails (and is perhaps entailed by) the possession of the higher-order belief that it is epistemically reasonable, or at least the willingness to form the corresponding higher-order judgement when considering the issue. The two mental phenomena in question seem to be of such kinds as to be much more distinct than that. We can be rational, have a well-functioning mind, and possess the concept of reasonableness (or even prima facie reasonableness), but, when asking which epistemic standing one of our judgements enjoys, still fail to apply the concept to the judgement. In particular, no aspect of this concept, or of our possession of it, tells us that it correctly applies to at least certain judgements. Recognizing that they enjoy such reasonableness amounts to a more substantial piece of knowledge..$^{22}$

Hence, the lower-order judgement, together with our consideration of its epistemic status, is perhaps better taken to reliably give rise to the higher-order judgement via some contingent and merely causal or informational relation. ${ }^{23}$ But apart from the general difficulties linked to causal reliabilism or informationalist semantics, this view faces the challenge to satisfactorily motivate the postulation of the respective internal mechanism. This mechanism would seem very odd and difficult to explain if such higher-order judgements spontaneously occurred

22 The assumption of a constitutive link is perhaps plausible with respect to higher-order ascriptions of propositional contents or attitudes (cf. Shoemaker 1994; Burge 1996; Wright 1998). But judgements about the reasonableness of other judgements are clearly of neither kind. And see Peacocke (1998), Martin (1998), and O’Brien (2003) for more general objections to the constitutive account and its central claim that higher- and lower-order states are not distinct entities. One particular worry is, for instance, that the postulated constitutive link between the lowerand higher-order states does not seem to provide the resources to explain how the latter can be epistemically grounded on, and constitute genuine instances of knowledge of, the former.

23 Peacocke's account of self-knowledge seems to open up a third possibility: to take the link to be rational, but non-constitutive. However, the considerations presented above against the applicability of constitutivist accounts also rule out the applicability of Peacocke's view, given that the latter, too, implies that the occurrence of the conscious lower-order states, together with our conceptual capacities and a rational and well-functioning mind, ensures that we are willing to form the higher-order judgements in the relevant circumstances (cf. Peacocke 1996). Besides, it is also interesting to note that Peacocke's account goes beyond the prompting model, and has some affinities to the experiential model, in that it assigns to consciousness an essential function in the epistemology of self-knowledge (cf. n. 28 below). 
solely in response to wondering about the epistemic standing of lower-order judgements, and not in response to wondering about some other feature or some other mental episode. But to widen the scope of the prompting model to other kinds of higher-order judgements seems to be plausible only in the context of endorsing an account of introspection, or self-knowledge, in terms of contingently but reliably prompted higher-order judgements. And such an account seems to be highly implausible, especially if applied to the kind of awareness under discussion. ${ }^{24}$ One specific problem is that the reasonableness of judgements seems to be among their features to which we can have direct introspective access only if they are indeed marked in phenomenal consciousness. The epistemic standing of judgements is at least in most cases a matter of their rational relations to reason-providing states or facts extrinsic to them. Therefore, if it is not reflected by an introspectible aspect of the experiential character of judgements, it can be recognized only by means of a cognitive process which encompasses more than the mere introspection of the judgement and its intrinsic features - a cognitive process which, for instance, combines introspection with inference and perhaps memory, as described above during the discussion of the inferential model. 25

However, if our primary awareness of the reasonableness of judgements is in at least many cases neither based on inferences, nor a matter of causally prompted higher-order judgements, then it should be taken to be experiential. No other plausible alternative suggests itself. Hence, taking our judgements to be epistemically appropriate should be best understood as experiencing them as enjoying the support of epistemic reasons - which again involves experiencing the judgements as being motivated by such reasons. Our higher-order judgements about the reasonableness of our lower-judgements may then be the result of introspecting this epistemic aspect of the phenomenal character of the latter.

As I have already mentioned, that judgements are always marked in phenomenal consciousness as occurring in response to reasons is compatible with the possibility that they are actually not so motivated, and that correspondingly our experiential awareness has failed us. We presumably react to such cases of error by taking ourselves to have forgotten about the specific rational origins

24 Among the more general objections to this account of introspection-which is endorsed, for instance, by Armstrong (1993) and Lycan (1996) — are: that it has to assume some form of causal reliabilism (cf. O'Brien 2003); that it cannot capture the transparency of mental content (cf. Dretske 1999); and that it does not link the lower- and higher-order states intimately enough to be able to account for the immediate rational impact of the latter on our revision of the former, for our related epistemic responsibility, and for the impossibility of brute error (i.e. error not due to the irrationality or malfunctioning of the subject) in the acquisition of self-knowledge (cf. Burge 1996; also Shoemaker 1994 and Siewert 1998).

${ }_{25}$ The same problem need not arise with respect to the introspection of externally determined contents, given that the contents of the higher-order states may embed the contents of the lowerorder states and thus can inform us about them without having to tell us something about their extrinsic relations (cf. Burge 1996; Peacocke 1996, 1998). 
of the judgements in question, or by coming to identify or construct new ones (e.g. by interpreting the mental causes of the judgements - say, certain desires or emotions - as their grounds). But our phenomenal awareness of judgements as rationally motivated is also compatible with the possibility of self-justifying judgements (if they are indeed a possibility). Such judgements provide epistemic support for themselves in virtue of some feature which they possess (e.g. their necessity, infallibility, certainty, etc.). And when we experience them as rationally motivated, we are aware of this rational relation in which they stand to themselves (e.g. by experiencing them as certain or self-evident). Nothing in what has been said so far suggests or even requires that we experience judgements as motivated by epistemic reasons distinct from themselves.

Much more problematic would be if some class of our judgements would allow for epistemic appropriateness despite not permitting any support by epistemic reasons, whether provided by the judgements themselves or by other states or facts. However, none of our judgements seem to be of such a kind. ${ }^{26}$ From an epistemic point of view, such states would be much more similar to perceptions than to normal judgements. Maybe intuitions, or intellectual seemings, may be of this type. Just like perceptions, they can perhaps be reliable or otherwise epistemically appropriate, without standing in rational relations supporting them. And just like perceptions, they are perhaps also immune to any rational influence of reasons. But judgements seem to be very different. Their epistemic appropriateness appears to be partly a matter of how well they cohere with our already existing beliefs (as well as other judgements). And this seems to mean, among other things, that the latter may provide us with (access to) reasons for, or against, the formation or revision of judgements. Moreover, our judgements appear to be sensitive to such reasons and react accordingly - say, by disappearing when they are in too great a tension with what else we believe.

\section{OUR EXPERIENCE OF MENTAL AGENCY}

What is left to be shown is how their feature of being experienced as epistemically motivated prevents judgements from being formed at will. In the remaining sections, I will argue for this incompatibility in three steps. First, I will try to make plausible that deliberate and straightforward mental agency (if successful) results in mental episodes which are always experienced by us as actively formed. Second, I will argue that this actually means that the respective episodes present themselves as occurring in immediate response to practical reasons. And

\footnotetext{
26 I take it that even perceptual judgements are not of this type, given that they are normally rationally supported by perceptions. See e.g. Martin (1993) and Cruz and Pollock (1999) for defences of this view.
} 
third, I will show that no mental episode can be experienced by us both as being epistemically motivated and as being immediately practically motivated. From this incompatibility between the two ways in which we may consciously experience mental episodes, it follows that our conscious judgements cannot result in a straightforward manner from our deliberate mental agency: for us, there cannot be any judgements formed at will.

I take it that our instances of deliberate mental agency (and presumably of deliberate agency in general) normally involve at least three elements (cf. e.g. Pink 1996). First of all, there are certain practical reasons which are potential motives for action, and which we are put in contact with by some of our mental states - say, intentions, desires, or other states with the capacity to move us to act. Then, there are the mental actions themselves which occur when we begin to act on some of the provided reasons. Examples are the straightforward acts of conjuring up an image or of making an explicit assumption. The mental actions may thereby be partly or wholly successful in bringing about the respective mental phenomena; or they may amount to something like mere attempts or tryings. And finally, there is the motivational link between the two other elements. The mental actions come into being once our practical reasons actually begin to move us. And these reasons continue to guide us throughout our performance of the resulting actions (cf. O’Brien 2003). According to this picture, practical motivation is - just like epistemic motivation - a rational (and presumably causal) relation; and it obtains precisely as long as the practical reasons stay effective in initiating and guiding the mental actions concerned.

Often, however, our mental actions involve, or at least give rise to, a fourth element: they bring about certain desired or intended mental phenomena as their results. Trying to conjure up an image of a sunny forest may actually produce such an image; while attempting to improve one's mood by conjuring up such an image may result in one's becoming happier. Furthermore, some of these results may be due to deliberate and straightforward mental agency. The representational episodes produced by, or as part of, acts of successful visualizing or supposing — such as the image of the sunny forest—are good examples.

Now, we typically can tell whether one of our mental episodes has been the result of our mental agency - at least, if it has been produced in a deliberate and straightforward way. When you pictured to yourself the sunny forest, or supposed that Goethe went to Stoos, you were presumably aware of the fact that you actively formed the respective representational episodes. And your awareness of them would presumably differ in this respect from the awareness you would have when perceiving a sunny forest, or judging that Goethe visited Stoos, or being confronted with the spontaneous and unbidden occurrence of an image or thought with a corresponding content. The main issue with which I will be concerned in the remainder of this section is how we can come to acquire this kind of awareness. And the plausible options seem to be the same as in the case 
of our awareness of the epistemic reasonableness of judgements: the inference, the prompting, and the experience model. ${ }^{27}$

As above, the inference model maintains that we inferentially arrive at our knowledge of the active origin of the respective mental episodes on the basis of introspection, and perhaps also memory or other forms of knowledge. A person successfully visualizing a sunny forest may, for instance, be introspectively aware of her intention - or of her attempt to act on her intention - to picture such a scene, as well as of the occurrence of the resulting image. Moreover, she may notice that these phenomena are temporally ordered, and that there is a match between the content of the intention or attempt at action and the nature of the subsequent visual episode. And she may possess general knowledge of the fact that such a combination of agreement and temporal order, which furthermore involves an intention or attempt to do something, is usually not accidental, but rather the consequence of the rational forces involved in practical motivation. Hence, the person may be able to draw the conclusion that the image of the forest has occurred, not spontaneously, but as the result of her own deliberate mental agency initiated by her intention.

However, the demands put by the inference model on the knowing subject are again too high. In order to come to know that some, but not others, of our mental episodes have been actively formed, we do not seem to have to possess knowledge of the non-accidental character and origin of the temporal order and match of the mental phenomena involved in mental agency. Nor do we seem to have to possess some of the concepts needed to entertain such knowledge or draw the inferences required (e.g. the concept of the kind of match described). In addition, our acquisition of the knowledge about the origin of our mental episodes appears, from a subjective point of view, to be more immediate than described by the inference model. It may be true that we infer the active or passive origin of a given episode in very special circumstances (e.g. when we are unsure about whether our primary way of acquiring this knowledge is working properly). But it seems that we typically do not need to engage in such elaborate reasoning in order to tell whether an episode is due to our own mental agency (cf. Peacocke 1998; O’Brien 2003).

According to the prompting model, the higher-order judgements about the active or passive origin of our mental episodes are not based on observation, inference, or experience, but instead reliably prompted by simply paying attention to the issue, or asking oneself the question, of how a certain present mental episode has been formed. Their occurrence is thus the product of some underlying causal or informational mechanism, which is set in motion by consciously addressing

27 An observational model can again be ruled out straight away (cf. O'Brien 2003). Although it has been argued that our primary knowledge of our own bodily actions is mediated by proprioception (cf. Dokic 2003), this idea obviously cannot be applied to mental agency. For the same reason, outer perception could not play a role. 
the topic of the origin of a given mental episode. And they reliably track the presence, or absence, of the special link obtaining between successful mental actions and the mental episodes which they have produced in a straightforward manner.

But this application of the prompting model is not very appealing, and mainly for the same reason as above, namely its difficulty in motivating the acceptance of the postulated internal mechanism. Again, it seems to make sense to speak of reliably prompted higher-order judgements only if they are taken to be introspective, or instances of self-knowledge. This idea is maybe more plausible this time, given that the straightforward results of our successful mental actions are perhaps constitutive parts of these actions (cf. Audi 1993), and introspecting the results and their active nature may therefore happen as part of introspecting the respective mental actions and their active nature. But it still seems valid that theories of introspection in line with the prompting model are much more plausible if they take the link between the lower- and the higherorder states to be constitutive rather than causal or informational (cf. n. 24 above). However, the possibility of a constitutive account does not arise, since we can satisfy all the relevant conditions concerning rationality, possession of concepts, and so on, without being inclined to judge a given lower-order mental episode to be actively or passively formed when asking ourselves the respective question. ${ }^{28}$

The experiential model seems, again, to be the best remaining alternative. It claims that we become aware of the active or passive origin of our mental episodes simply by having and experiencing them. In particular, we experience the mental episodes resulting straightforwardly from our deliberate mental agency as actively formed, while we presumably experience most or all other mental episodes as having occurred in a passive manner. This is one reason why we experience a

28 See O'Brien (2003) for more general criticism of the constitutivist approach to our selfknowledge of our conscious actions. Her own account of such self-knowledge is formulated along the lines of Peacocke's account of our self-knowledge of conscious states. Accordingly, it assumes a rational, but non-constitutive link between our actions and our self-knowledge of them, as well as an essential role for the way in which we are conscious of our own actions, namely by means of a '[conscious] sense of guiding our action, . . . a sense of control' (ibid. 378). The latter aspect of her theory seems to be very close to my idea that we experience our mental actions as motivated and guided by practical reasons and renders her view more akin to the experiential than to the prompting model.

Peacocke's own view on our self-knowledge of (bodily) agency also assigns an essential epistemic role to our non-observational conscious experience (or 'awareness from the inside') in the formation of the higher-order judgement or belief that we are, or have been, successfully trying to do something, at least in the case of basic or straightforward agency. Moreover, he takes the respective experience to be an awareness of successfully trying (cf. Peacocke 2003: 103 and 105; and Ch. 10 below). Hence, the awareness may very well extend (as proposed by the experiential model) to that mental episode the occurrence of which renders the respective attempt at mental action successful. It is, however, unclear whether what he has in mind here is the way we phenomenally experience actions - i.e. a phenomenal property of the episodes of acting themselves; or instead independent and non-judgemental conscious states representing our mental actions (cf. Ch. 10). 
deliberately formed image of a sunny forest differently from a perception or a spontaneous or remembered image of such a scene.

This picture fits very well with (but does not entail) the view that our primary awareness of the active character of our deliberate mental actions is experiential, too. And the truth of this further view would suggest (but, again, not imply) that the straightforward results of our deliberate mental actions, given that they are experienced in the same way as the mental actions itself, are constitutive parts of the latter. The fact that we experience certain mental phenomena as active may thus perhaps serve as a guide to agency: if we experience something as active, then it normally is an instance of agency. However, the opposite does not seem to be true: we do not appear to experience all instances or parts of action as active. Most, if not all, examples of non-deliberate agency seem to lack the kind of attentive conscious awareness of activity characteristic of deliberate agency (cf. O'Shaughnessy 1980; Pink 1996). And when we intentionally improve our mood by imagining something cheerful, we do not seem to experience the resulting change in mood as actively produced, but only the images and thoughts involved in bringing about that change. Given that the deliberate improvement of one's mood is none the less an instance of mediated agency, this suggests that our experience of passivity does not always reveal all aspects of the origin of the respective mental episodes. It discloses the direct passive origination in, say, some epistemic or merely causal processes. But it does not also reveal the prior deliberate mental activity which has started these processes. Therefore, this ultimately suggests that our experience of activity is solely or primarily a guide to deliberate and straightforward agency.

\section{THE INCOMPATIBILITY OF THE TWO KINDS OF EXPERIENCE}

This leads directly to the question of what it means to experience a mental phenomenon as active. My answer to this question is that the respective experience reveals at least two aspects of the mental agency concerned: that it is practically motivated; and that it is so motivated in an immediate manner. This may explain, among other things, why our experience of activity may very well be a guide to straightforward agency, assuming that, normally, the phenomenal character of our conscious mental states and events adequately reflects their nature.

It appears very natural to say that our mental phenomena, which are marked in phenomenal consciousness as active, present themselves thereby as practically motivated. Experiencing some action or episode as practically motivated means experiencing it as rationally responding to certain practical reasons. And our deliberate mental actions (including our not entirely unsuccessful attempts at them) are indeed sensitive to reasons in this way: they are initiated and guided 
throughout their performance by practical reasons provided to us by our desires, intentions, or similar states. In fact, if our experience of our deliberate mental actions did not reflect this sensitivity to reasons, it would not make much sense to call it an experience of activity at all: practical motivation seems to be at the heart of agency. Not surprisingly, when theorists talk about how actions present themselves to us in phenomenal consciousness, they often resort to characterizations very similar to mine. ${ }^{29}$ And of course, our experiential awareness of practical motivation is - just like our experience of epistemic motivation - possibly non-conceptual, minimal, fallible, and non-distinctive in the senses specified above.

However, my claim has been not only that we experience the results of our deliberate and straightforward mental agency as practically motivated; but also that we experience the straightforwardness of their motivation, meaning that we experience them as immediately responding to the respective practical reasons. To understand and support this thesis, it is helpful to consider first what it could mean to experience some mental episode as responding to practical reasons in a mediated way.

As already mentioned, mediated mental agency is characterized by the fact that it —often deliberately — relies on certain passive processes in order to bring about certain mental phenomena. For instance, when we act on the intention to finally force a conclusion on a certain matter in the light of the epistemic reasons already available to us, we usually do so with the expectation that the respective epistemic processes or mechanisms triggered by us are likely to compel us to endorse the proposition which best reflects our epistemic reasons. Now, our experience of successfully forming a judgement in this way shows two aspects, which correspond to two elements involved in such a formation. First, our initial attempt to come to a conclusion by setting in motion certain epistemic processes presents itself in phenomenal consciousness as active: we are aware of it as a rational response to our underlying desire or intention to force the issue. But second, the subsequently occurring impact of the triggered epistemic mechanisms presents itself to us as passive: we are aware of the compelling force of the epistemic reasons on our formation of the judgement and, more precisely, on our actually drawing one particular conclusion, rather than another. Accordingly, our complex experience of intentionally forming a judgement on the basis of evidence has a double character: it involves both an experience of the support provided by practical reasons and an experience of the influence of the epistemic mechanisms. And something similar will be true for other examples of mediated mental agency, whether they rely on epistemic

29 In addition to O'Brien (cf. n. 28 above), Audi speaks of a 'phenomenal sense of acting in response' to some reason (1993: 154), Wegner of a 'feeling of voluntariness or doing a thing "on purpose" ' or of an 'experience of consciously willing an action' (2004: 650), and Siegel of a 'special sense or experience of carrying out an intentional action' (2005: 280). 
processes (as when we deliberately try to remember something) or on merely causal ones (as when we deliberately try to influence our mood by imagining something).

Because the effects of the passive processes deliberately triggered by us occur often almost immediately after we have begun (and finished) to perform the respective action, it might seem as if we experience a single mental phenomenon as both active and passive. But cases in which we fail to form a judgement despite all our attempts - say, because our evidence does not favour one conclusion over another and thus lets the epistemic mechanisms run idle-indicate that there are in fact two distinct phenomena with two distinct experiential characters. The mental action of setting in motion the epistemic processes (i.e. the attempt to judge the issue) is experienced as active, while the subsequent output of those processes (i.e. the judgement) is experienced as passive. Other cases, in which there is much more delay between the trigger and the product of the passive processes involved, or in which the triggering action is bodily, make this even clearer (cf. the example of inducing a judgement by deliberately taking a slow-acting drug).

Our experience of successfully forming a mental episode in a more straightforward way, on the other hand, does not show such a double character. Deliberately conjuring up an image will involve the awareness of the impact of practical motivation on the resulting image, but not the awareness of the impact of some epistemic or causal processes. Of course, we may sometimes become aware of some obstacles beyond our influence when attempting to perform a certain straightforward mental action. And we may experience their impact on us in a very similar way to how we experience the force of the epistemic or causal processes in the examples of deliberate mediated agency. For instance, when trying to visualize an object with twenty equal sides, we may realize that we cannot do this, and our attempt and recognition of failure may be accompanied by a strong feeling of the imposition of respective limits on our capacities involved. But if we succeed in forming the image, no such awareness of an obstacle or an external force will occur. Similarly, our choice of what to visualize may be influenced by epistemic considerations, and we may be consciously aware of this fact (e.g. when we decide to visualize a sunny forest partly because of concluding that this will calm us down). But this awareness of an epistemic impact will be part of our formation of the respective desire or intention to visualize. And it will therefore precede our straightforward agency of visualizing, as well as our experience of our engagement in this activity. ${ }^{30}$

30 The case of guessing is equally unproblematic, but slightly more complicated, given that any potential impact of the evidence available to us need not precede our active choice of which proposition to accept, but instead may restrict it during our active engagement with it (cf. the experience of external objects as restricting our active bodily movement). In the light of what has been said above (cf. esp. n. 4 above), the agency constitutive of guessing counts as straightforward, despite the potential involvement of epistemic factors. For what we guess (in contrast to what we judge) 
These considerations about the various ways in which we can deliberately influence what happens in our minds illustrate that our experiential awareness of mental agency seems indeed to be restricted to deliberate and straightforward agency and its mental products. But they equally link up to the observation that this kind of experience reflects especially the straightforwardness of the kind of agency concerned. For we experience the (not necessarily temporal) immediacy of determination with which the direct results of deliberate mental agency occur in response to the respective practical reasons. The idea is that we experience the mental episodes which we intentionally produce without exploiting certain passive processes as directly determined by and flowing from our motives and our attempts to act on them. And it is an essential part of this experience of immediacy that we are not aware of any determining factors other than practical motivation. In other words, we experience the immediacy of the practical motivation partly by not being conscious of any other determining factors as intervening between our desire or intention and the formed images, apart from our mental agency. When we visualize a sunny forest, we experience the resulting visual image as a direct response to our attempt to visualize a sunny forest and, given that this attempt flows immediately from our respective desire or intention, also as a direct response to the latter.

By contrast, the mental episodes produced in a mediated way by our deliberate mental activity do not present themselves as immediately responding to our practical motives, given that they are experienced as determined by epistemic or causal processes. When we intentionally form a judgement on the basis of the evidence available to us, we are aware of the compelling impact of the epistemic considerations determining which particular proposition we end up endorsing. And this aspect of our experience of the judgement is responsible for the fact that it cannot count as an experience of immediate practical motivation, given that this experience of immediacy requires the absence of any awareness of determining elements other than practical motives. This is precisely the reason why the phenomenal character of our judgements is incompatible with the phenomenal character of mental episodes resulting from our deliberate mental agency in a straightforward way. For independently of whether our judgements are actually motivated by epistemic reasons, they always phenomenally present themselves to us as such. And this experiential awareness of an epistemic rational influence would undermine - for the reason just mentioned — any awareness of an immediate motivational impact of practical reasons. But such an awareness of immediacy is always part of how we experience straightforwardly formed episodes. Hence, none of our mental episodes can be phenomenally marked

is ultimately a matter of our choice (cf. n. 4). Moreover, the related experience of straightforward agency is compatible with the potential simultaneous awareness of epistemic influence and limitation, given that the latter is never experienced as fully determining what is guessed (in contrast to what is judged), but as leaving room for the experience of the immediate impact of the practical reasons concerned. 
for us both as a judgement and as a product of deliberate and straightforward mental agency. And this explains why we cannot form judgements at will: we would have to consciously experience the resulting episodes in a way which is not open to us.

The fact that our experience of the immediacy of the practical motivation of a given mental episode is incompatible with our simultaneous experience of the same episode as occurring in response to epistemic motivation is perhaps more fundamentally due to the fact that the respective two phenomenal aspects reflect incompatible features of our episodes. Since no episode can be both epistemically and straightforwardly practically motivated, it seems that, if one aspect of the experiential character of one of our episodes adequately reflects its epistemic motivation, another aspect cannot simultaneously adequately reflect the straightforward practical motivation of the episode. Similarly, that we cannot properly experience a perception both as representing red and as representing green is maybe primarily due, not to how such perceptions actually present themselves to us in phenomenal consciousness, but to the underlying fact that a red-perception cannot simultaneously (and with respect to the same part of an object) be a green-perception. Consequently, the incompatibility at issue may be located only derivatively in how we experience the respective mental episodes, and ultimately in which role these experiences play in our mental lives, namely to reveal the nature of the episodes concerned. ${ }^{31}$

Given that - as already noted before-our experiential awareness is fallible, it might however still be possible that we can actively form a judgement in direct and conscious response to some of our desires or intentions, as long as we do not experience the resulting judgement as a judgement, that is, as epistemically motivated. ${ }^{32}$ But such a case would not count as an instance

31 The preceding considerations apply equally well to the many mental phenomena, which mix imaginative or otherwise straightforwardly active elements with more passive-and often cognitive-elements. Deliberately trying to visualize a particular friend as sitting in the chair opposite to me will involve seeing the chair, actively recalling his appearance and imaginatively combining and manipulating the 'sensory material' thereby provided to conjure up the image of him sitting in the chair. And while the perceptual element occurs in a purely passive way, both the mnemonic and the imaginative element involve conscious agency, albeit the former in a mediated and the latter in a straightforward manner. What we thereby experience as active is precisely what we do straightforwardly: namely, whatever needs to be done to trigger the respective mnemonic process, as well as our conjuring up the image by using the provided 'sensory material'. And the same seems true of other more complex forms of mental agency. Calculating a sum in one's head, for instance, consists in actively triggering a series of epistemic processes (e.g. those providing us with the result of adding or multiplying two numbers). But although the impact of these processes is experienced as passive, we actively trigger them in a mediated way by means of performing a more basic straightforward action, coming with the respective experience of agency. And a last example is cases of visualizing where some of the details of the resulting image are passively 'filled in' by the mind (e.g. due to our knowledge or memory of generic appearances) and experienced as such, although the other aspects of the image are experienced as immediately determined by our imaginative agency.

32 Thanks to Lucy O’Brien for pointing out this possibility. 
of deliberately forming a judgement in a straightforward manner. We might have performed the described action on the basis of a desire or intention to form a supposition; and a mistake might then have led to the occurrence of a judgement experienced as a supposition. But then, we would have tried to form a supposition, and not a judgement. Alternatively, we might have intentionally set out to form a judgement in such a way that it is not experienced by us as a judgement. But then, we would have had to exploit some passive processes bringing about this phenomenal illusion and, hence, would not have formed the judgement in a straightforward manner. There is perhaps also the possibility that we might come up with and might act on the intention to form a judgement at will in such a way as to fail to experience it as the straightforward product of mental agency (i.e. as immediately practically motivated). But our action could not be successful, given that the satisfaction of the two intended goals - the straightforward formation of the judgement and the creation of the phenomenal illusion - dictates incompatible means. Since we cannot bring about phenomenal illusions at will, the achievement of the second goal requires the reliance on certain causal processes. But it is precisely such a form of mediated agency which is ruled out by the successful straightforward formation of the judgement.

It has also been argued that our phenomenal experience is systematically misleading with respect to the nature of our minds: either because there are no instances of judging, imagining, or deliberate mental agency, despite it seeming to us that way; or because there are such instances, but they are not as they seem to us to be (cf. the eliminativist approaches to phenomenal consciousness). Here is not the place to assess the respective arguments, but let me briefly note the consequences their soundness would have for the experiential approach to the involuntariness of judgements. If none of the mental phenomena at issue existed, the question of whether we can form judgements at will would not arise, but instead only the question of why it none the less seems to us as if there is a difference between judging and imagining in respect to (what merely appears to us to be) deliberateness and straightforwardness. The normative approach could not hope to answer this question about our phenomenology: if there were no judgements, then there would also be no norms for judgements. The experiential approach, on the other hand, would still have something to say about the difference between judging and imagining and would also have good chances to be compatible with the - presumably causal and subpersonal-account of why things erroneously seem to us a certain way in the first place. On the other hand, that our phenomenal experience might turn out to generally misrepresent certain aspects of the nature of our mental phenomena would not pose any problem for the experiential approach, as long as the latter remains true of how we actually do experience judgements and mental actions. If the phenomenal illusion concerned the seeming rational motivation of judgements or deliberate mental actions, this would in fact mean, again, that there are no judgements or deliberate mental 
actions, given that it is essential to these mental phenomena that they are rational and normally rationally motivated. And if the phenomenal illusion concerned some other aspect of the nature of judgements or deliberate mental actions, this error would be irrelevant for the question of whether judgements can be formed at will. For instance, it might indeed be the case that our actions are caused by certain sub-personal factors in our minds, although we experience them as originating in our tryings or volitions, or in us as conscious agents (cf. Wegner 2004). But our awareness of deliberate and straightforward activity would still be correlated to the respective instances of mental agency; and it would still be incompatible with our awareness of judgements.

\section{CONCLUSION AND OUTLOOK}

What I have been trying to show is that the experiential approach succeeds in establishing two things: the psychological and non-normative constraint on all our possible judgements that they are always experienced by us as epistemically motivated; and the incompatibility of this constraint with their deliberate and straightforward formation and, in particular, with experiencing them as formed in such a way. My main conclusion is therefore indeed that, for us, judging cannot be active and deliberate in the same straightforward way in which imagining can be active and deliberate. But the preceding considerations have also further substantiated the idea that our conscious experience of agency is a guide to-and only to-deliberate and straightforward agency, at least if mental activity is concerned. If something mental is experienced as active, it is normally part of deliberate mental agency. Our awareness of mental passivity, on the other hand, seems less revelatory, given that it is still compatible with more mediated forms of deliberate agency, such as in the example of intentionally changing one's mood and, indeed, in cases of deliberately forming judgements on the basis of evidence.

The experiential approach is compatible with the idea that it is possible to conceive of judgements as being formed at will, and to desire or intend to form a particular judgement in this way. All it claims is that we are bound to fail if we consciously try to act on such a desire or intention. In this respect, it is likely to contradict the version of the normative approach which assumes that the truth norm (TN), and presumably also something like the constraint $(\mathrm{C})$, are part of our concept of judgements, and that we have to employ this concept when aiming to form a judgement or classifying a mental episode as a judgement. Given the presupposition of certain further conceptual links (e.g. between truth and evidence), this assumption may be said - following an argument similar to the one presented during the discussion of $(\mathrm{C})$ - to entail that we cannot conceive of judgements as formed at will. And this again seems to imply that we cannot deliberately produce them in a straightforward manner: either because we 
cannot form the required desires or intentions in the first place; or because our necessary failure to conceive of judgements as judgements after their deliberate and straightforward formation would prevent us from acquiring the knowledge that we can perform this kind of action, while such knowledge appears to be necessary for deliberate agency. ${ }^{33}$ But apart from the fact that the objections against the normative approach mentioned above also apply to this more complex version of it, the latter faces its own specific difficulties. Notably, it seems very doubtful that it can establish all the conceptual truths required; or, indeed, the claim that we (including children) have to possess and employ such a rich concept of judgements in order, say, to decide to make up our minds about a certain issue, or to desire forming a particular judgement (e.g. by some manipulative means) because it would make us happier if we did.

But the experiential approach has other advantages over the normative approach, in all its facets. Not only can it easily accommodate the deliberate formation of manipulated or induced judgements, it also promises to be extendable to non-normative involuntary mental episodes. The normative approach has nothing to say about why we cannot form, say, perceptions, sensations or feelings at will, given that these phenomena are not subject to norms or requirements similar to (TN) or (C). By contrast, all kinds of involuntary mental episodes are phenomenally conscious and thus permit, at least in principle, the application of an argument which concentrates on this feature of them. It may be argued, for instance, that the causal determination of perceptions or sensations by those aspects of the world or our bodies, which they inform us about, becomes salient in their phenomenal character; and that this aspect of how we experience them is, again, incompatible with experiencing the immediacy involved in deliberate and straightforward mental agency. The experiential approach may therefore allow for a much more unified account of the involuntariness to be found in our conscious mental lives than the normative approach.

If the experiential approach indeed turns out to be the right one, then the involuntariness of our judgements is a matter of our psychology, and not of our concepts: it depends first of all on how we, as a matter of fact, experience judgements and mental actions. This leaves room for the possibility that the involuntariness of our judgements is merely contingent, and that there might be other creatures who experience these mental phenomena in very different ways and, hence, may still be able to form judgements at will. So far, the experiential approach has said nothing about this possibility. But it might perhaps be supplemented in such a way as to rule it out and thus to ensure the necessity of our inability to form judgements at will. The idea would be that the rational aspect of the actual phenomenal character of our judgements and mental actions is essential not only to how we in fact experience these conscious

33 This seems to come very close to the first argument against voluntary beliefs to be found in Williams (1973). 
mental phenomena, but also to how any potential being having them would experience them. And this might perhaps be traced back to the idea that the underlying rational nature of the respective phenomena can be phenomenally revealed to subjects experiencing them solely in the way in which it is actually disclosed to us - say, because how we experience these phenomena is constitutive of, or constituted by, or otherwise inseparably linked to, how they really are. This would still allow for experiential differences among subjects both of the same and of distinct species, as long as they do not concern the phenomenal disclosure of their rational nature (or of the respective aspects thereof). But the latter would necessarily be salient to all subjects in the same way and, hence, give rise to the same phenomenal incompatibilities. This would explain why we experience judgements and mental actions the way we experience them: as of necessity, to experience some mental phenomenon as a judgement or as a mental action would just mean, partly, to experience it as occurring in response to reasons. However, it would perhaps also imply that our experiential awareness of the rational aspects of our conscious minds is not primitive, and that a more fundamental account of it and of why we cannot form judgements at will can be formulated-namely in terms of those of their features which are constitutively linked to their phenomenal character and ultimately make up their nature. ${ }^{34}$

\section{REFERENCES}

Armstrong, David (1993) A Materialist Theory of Mind (London: Routledge).

Audi, Robert (1993) Action, Intention, and Reason (Ithaca, NY: Cornell University Press). Bennett, Jonathan (1990) 'Why is Belief Involuntary?', Analysis, 50: 87-107.

Bodrozic, Davor (ed.) (2004) 'Intuition and Epistemology', Dialectica, 58: 3-10.

Burge, Tyler (1996) 'Our Entitlement to Self-Knowledge', Proceedings of the Aristotelian Society, 96: 91-116.

Carruthers, Peter (2000) Phenomenal Consciousness: A Naturalistic Theory (Cambridge: Cambridge University Press).

Cruz, Joseph, and John Pollock (1999) Contemporary Theories of Knowledge (Lanham, MD: Rowman \& Littlefield).

34 Various versions of this chapter have been presented at a one-day conference on mental agency in Senate House, London, the research colloquium at the University of Fribourg, the SOPHA meeting 2006 in Aix-en-Provence, and a conference on the phenomenology of agency, again at the University of Fribourg. For very helpful comments on these occasions, I would like to thank Julien Deonna, Julien Dutant, Pascal Engel, Guy Longworth, Martine Nida-Rümelin, Chris Peacocke, Joelle Proust, Nishi Shah, Joel Smith, Gianfranco Soldati, Juan Suarez, Fabrice Terroni, Stephen White, and Ann Whittle. For reading previous drafts and providing extensive comments, I am extremely grateful to Davor Bodrozic, Adrian Haddock, Lucy O’Brien, Matthew Soteriou, Gian-Andri Toendury, and an anonymous referee. I would also like to thank the Swiss National Science Foundation for funding part of the work on this chapter. 
Dokic, Jérôme (2003) 'The Sense of Ownership: An Analogy between Sensation and Action', in Naomi Eilan and Johannes Roessler (eds.), Agency and Self-Awareness (Oxford: Oxford University Press), 321-44.

Dorsch, Fabian (2009) The Unity of Imagining (Frankfurt and Lancaster: Ontos Publishing House).

— and Gianfranco Soldati (2004) 'Conceptual Qualia and Communication', http://projectsfinal.interaction-ivrea.it/2004-2005/SYMPOSIUM 2005/communica tion material/.

Dretske, Frederick (1999) 'The Mind's Awareness of Itself', Philosophical Studies, 95: $103-24$.

- (2000) 'Norms, History, and the Constitution of the Mental', in Perception, Knowledge and Belief (Cambridge: Cambridge University Press), 242-58.

Engel, Pascal (2002) 'Volitionism and Voluntarism about Belief', Croatian Journal of Philosophy, 2: 267-79.

Hornsby, Jennifer (1980) Actions (London: Routledge).

- (2005) 'Knowledge and Action', unpublished.

Lycan, William G. (1996) Consciousness and Experience (Cambridge, MA: MIT Press).

Martin, M. G. F. (1993) 'The Rational Role of Experience', Proceedings of the Aristotelian Society, 93: 71-88.

- (1997) 'Self-Observation', European Journal of Philosophy, 5: 119-40.

(1998) 'An Eye Directed Outward', in Cynthia MacDonald, Barry C. Smith, and Crispin Wright (eds.), Knowing Our Own Minds (Oxford: Oxford University Press), 99-121.

Noordhof, Paul (2001) 'Believe What You Want', Proceedings of the Aristotelian Society, 101: $247-65$.

O’Brien, Lucy (2003) 'On Knowing One's Own Actions', in Naomi Eilan and Johannes Roessler (eds.), Agency and Self-Awareness (Oxford: Oxford University Press), $358-82$.

O'Shaughnessy, Brian (1980) The Will (Cambridge: Cambridge University Press).

Owens, David (2000) Reason Without Freedom (London: Routledge).

- (2003) 'Does Belief Have an Aim?', Philosophical Studies, 115: 282-305.

Papineau, David (1999) 'Normativity and Judgement', Supplement to the Proceedings of the Aristotelian Society, 73: 16-43.

Peacocke, Christopher (1996) 'Entitlement, Self-Knowledge and Conceptual Redeployment', Proceedings of the Aristotelian Society, 96: 117-58.

- (1998) 'Conscious Attitudes, Attention, and Self-Knowledge', in Cynthia MacDonald, Barry C. Smith, and Crispin Wright (eds.), Knowing Our Own Minds (Oxford: Oxford University Press), 63-97.

- (2003) 'Action: Awareness, Ownership, and Knowledge', in Naomi Eilan and Johannes Roessler (eds.), Agency and Self-Awareness (Oxford: Oxford University Press), 94-110.

Pink, Thomas (1996) The Psychology of Freedom (Cambridge: Cambridge University Press).

Shah, Nishi (2003) 'How Truth Governs Belief', Philosophical Review, 112: 447-82.

— and David Velleman (2005) 'Doxastic Deliberation', Philosophical Review, 114: 497-534. 
Shoemaker, Sidney (1994) 'Self-Knowledge and "Inner Sense"', Philosophy and Phenomenological Research, 54: 249-314.

Siegel, Susanna (2005) 'The Phenomenology of Efficacy', Philosophical Topics, 33: 265-84.

Siewert, Charles (1998) The Significance of Consciousness (Princeton: Princeton University Press).

Wedgwood, Ralph (2002) 'The Aim of Belief', Philosophical Perspectives, 16: 267-97.

Wegner, Daniel M. (2004) 'Précis of: The Illusion of Conscious Will', Behavioral and Brain Sciences, 27: 649-92.

Weatherson, Brian (2007) 'Deontology and Descartes' Demon', http://brian.weatherson. org/ddd.pdf.

Williams, Bernard (1973) 'Deciding to Believe', in Problems of the Self (Cambridge: Cambridge University Press), 136-51.

Williamson, Timothy (2000) Knowledge and its Limits (Oxford: Oxford University Press).

Winters, Barbara (1979) 'Believing at Will', Journal of Philosophy, 76: 243-56.

Wollheim, Richard (1984) The Thread of Life (New Haven, CT: Yale University Press). Wright, Crispin (1998) 'Self-Knowledge: The Wittgensteinian Legacy', in Crispin Wright, Barry C. Smith, and Cynthia MacDonald (eds.), Knowing Our Own Minds (Oxford: Oxford University Press), 15-45. 